\title{
A FAMÍLIA PARA CRIANÇAS E ADOLESCENTES VITIMIZADOS
}

THE FAMILY FOR CHILDREN AND ADOLESCENTS VICTIMS

\author{
LA FAMILIA PARA NIÑOS Y ADOLESCENTES VICTIMADOS
}

\author{
Fabiola Perri Venturini* \\ Zelia Maria Mendes Biasoli-Alves** \\ Mirian Botelho Sagim ${ }^{\star * *}$ \\ Vanessa Delfino****
}

\footnotetext{
* Doutoranda do Programa de Pós-Graduação em Psicologia do Departamento de Psicologia e Educação da Faculdade de Filosofia, Ciências e Letras de Ribeirão Preto da USP.

** Professora Titular do Departamento de Psicologia e Educação da Faculdade de Filosofia, Ciências e Letras de Ribeirão Preto da USP.

*** Doutoranda do Programa de Pós-Graduação em Psicologia do Departamento de Psicologia e Educação da Faculdade de Filosofia, Ciências e Letras de Ribeirão Preto da USP.

**** Doutoranda do Programa de Pós-Graduação em Psicologia do Departamento de Psicologia e Educação da Faculdade de Filosofia, Ciências e Letras de Ribeirão Preto da Universidade de São Paulo (USP).
}

RESUMO. A presente pesquisa exploratória teve por objetivo estudar o fenômeno da violência doméstica pela ótica de crianças e adolescentes abrigados devido a maus-tratos, investigando suas concepções de família, e comparando-as com as de um grupo de jovens não-vitimizados provenientes de uma escola da rede pública. Participaram desse estudo 44 crianças e adolescentes, de ambos os sexos, com idades entre 10 e 16 anos. Foram utilizados como estratégia para coleta de dados 3 instrumentos complementares entre si: uma entrevista estruturada que visou obter os dados sócio-demográficos dos participantes, um questionário composto por "sentenças incompletas" e uma entrevista semi-estruturada que investigavam as percepções sobre família. Os instrumentos foram aplicados individualmente. A análise de dados foi feita seguindo-se o modelo quantitativo-interpretativo e permitiu algumas conclusões: 1) não foram encontradas diferenças significativas entre as concepções dos dois grupos e houve uma tendência a respostas de caráter convencional; 2) houve um grande número de respostas evasivas sendo a freqüência maior no grupo dos jovens abrigados; 3) observou-se uma tendência à "naturalização" da violência em ambos os grupos, porém mais freqüente no grupo de não vitimizados e 4) um desejo dos jovens abrigados de estarem com suas famílias.

PALAVRAS-CHAVE: família; violência doméstica; criança; adolescente.

ABSTRACT. The present exploratory study investigated the ideas about violence's phenomenon of children and adolescents who were institutionalized they were victims of domestic violence, comparing these ideas with the ideas from a group composed of children and adolescents who were not victims of domestic violence. The 44 participants from 10 to 16 years old, answered 3 complementary instruments: a structured interview, a questionnaire composed of "Incomplete Sentences" and a semi-structured interview. The analysis allowed some conclusions: 1) It was not found significant differences between the two groups and there was a tendency to conventional answers; 2) There was a lot of evasive answers, with higher frequency in the victimized group; 3) There was a tendency to the "naturalization" of violence in both groups, although with a higher frequency in the non-victimized group and 4) a wish of the victimized group being (live) with their families.

KEYWORDS: family; domestic violence; child; adolescent.

RESUMEN. El presente estudio exploratorio tiene por objetivo estudiar el fenómeno de la violencia domestica por la óptica de niños y adolescentes en resguardo debido a mal tratos, investigando sus concepciones de la familia, y comparando con las de un grupo de jóvenes no victimados, de una escuela de la red publica. Participaron de este estudio 44 niños y adolescentes, de ambos sexos con edad entre 10 y 16 años. Fueron utilizados como estrategia para la colecta de datos tres instrumentos elaborados para esta encuesta que son complementarios entre si: a) una entrevista estructurada que hizo obtener los datos socio demográficos de los participantes; b) un cuestionario compuesto por "sentencias incompletas"; e) una entrevista semi estructurada que investigaba las percepciones sobre la familia. Los instrumentos fueron aplicados individualmente y permitió algunas conclusiones: 1) no fueron encontrados diferencias significantes entre las concepciones de los dos grupos y hubo una tendencia a respuestas de carácter convencional; 2) hubo un gran numero de respuestas evasivas siendo la frecuencia mayor en el grupo de los jóvenes resguardados; 3) observo una tendencia a "naturalización" de la violencia en ambos los grupos, siendo más frecuente en el grupo de no victimados y 4) un deseo de los jóvenes resguardados de estar con sus familias.

PALABRAS-CLAVE: familia; violencia domestica; niño; adolescente.

Recebido em: 21/03/2005

Aceito em: 27/07/2005
Zelia Maria Mendes Biasoli-Alves

Av. Bandeirantes, 3900 - Monte Alegre

14040-901 - Ribeirão Preto - SP

E-mail: zmmbiasoli@terra.com.br 


\section{INTRODUÇÃO}

A violência não é fenômeno social exclusivo de nossa época, mas sim resultado de uma cultura que vem se estabelecendo ao longo da história, na qual as relações de poder desempenham papel fundamental. Essas relações são intensamente permeadas por questões de gênero e de hierarquia, resultando numa sociedade preponderantemente adultocêntrica e machista em que, deduz-se, o segmento social mais frágil é o da mulher-criança ${ }^{1}$.

No tocante à vitimização de crianças e adolescentes dentro dos lares, é possível especificar que esta seria inerente a relações subjetivas, interpessoais e hierárquicas, em que há um abuso do poder característico, por parte do adulto responsável ${ }^{2}$. Em outras palavras, a violência doméstica é geralmente caracterizada por um abuso do poder disciplinador e coercitivo dos pais ou responsáveis, em que a vítima é completamente objetalizada e seus direitos fundamentais, como a vida, a liberdade e a segurança, são desrespeitados. Essa sujeição de jovens a diversas formas de maustratos no ambiente familiar pode ter duração indefinida devido a sacralidade dessa instituição e à autoridade que os pais exercem sobre seus filhos, impondo-lhes um pacto de silêncio e, por vezes, de cumplicidade ${ }^{3}$.

Em termos operacionais, ela compreenderia "(...) qualquer dano físico ou psicológico não acidental contra um menor de dezesseis ou dezoito anos segundo o regime de cada país -, ocasionado por seus pais ou cuidadores, que ocorre como resultado de ações físicas, sexuais ou emocionais, por omissão ou comissão, e que ameaçam o desenvolvimento normal, tanto físico como psicológico da criança" ${ }^{4: 40}$.

As conseqüências decorrentes deste tipo de vivência parecem ser inúmeras, porém há certa dificuldade em descrevê-las de modo sistemático, pois, em algumas vítimas, as seqüelas são agravadas ou adiadas com o tempo, manifestam-se tardiamente ou, ainda, há quem possa ser considerado como "assintomático" 5.

Considerando as vítimas que apresentam alguma manifestação como conseqüência dessa violência peculiar, a literatura aponta a existência de problemas desde orgânicos até emocionais e/ou psicossociais, podendo-se destacar, de maneira geral, os danos no desenvolvimento neurológico, intelectual, emocional, a baixa auto-estima, os comportamentos agressivos, o isolamento, as dificuldades de relacionamento, depressão, ideação de homicídio, ideação de suicídio, dificuldade de adaptação sexual, sentimento de culpa, abandono da escola, prostituição e rejeição familiar. Essas conseqüências repercutem na vida das crianças/adolescentes vitimizados, tanto a curto como a longo prazo ${ }^{6}$.

Uma relação de violência na infância produz problemas que certamente se manifestarão na relação com outras pessoas. Assim, esses jovens, em relação aos que não sofreram maus tratos, apresentam um número alto de vínculos inseguros e frente a adultos não familiares, apresentam um maior número de condutas de evitação ?

Nas relações com pares, as crianças maltratadas tendem a exibir uma maior agressividade e uma menor tolerância à frustração. Portanto, é possível observar condutas anti-sociais nessas crianças decorrentes de dificuldades em assumir as perspectivas do outro e discriminar suas emoções. Essas atitudes indicam sua dificuldade para desenvolver um modelo de relação simétrico, baseado no sentimento de igualdade e de confiança, visto que suas experiências são caracterizadas pela exploração, submissão e violação da confiança ${ }^{8}$.

Essas crianças carecem de confiança em si mesmos, suas perspectivas de futuro são incertas além de expressarem mais freqüentemente sintomas de tristeza e depressão ${ }^{7}$. Também é freqüente observar atrasos no desenvolvimento cognitivo, decorrente de uma lenta aquisição de habilidades de aprendizagem, concorrendo para a repetência e conseqüente atraso escolar.

Em relação ao desenvolvimento moral, embora esta dimensão ainda necessite ser mais estudada, as crianças maltratadas manifestam uma compreensão deficiente de regras sociais e, citando alguns estudos, destacam que as vítimas de maus-tratos constroem 
seus juízos morais e sociais a partir de suas experiências e, portanto, podem internalizar padrões de conduta que refletem as normas/valores subjacentes às experiências de abuso/negligência ${ }^{4}$.

Aber, Allen, Carlson e Cicchetti, realizando um estudo comparativo entre crianças vitimizadas e não vitimizadas, com idade variando entre os 4 a 8 anos, com o objetivo de verificar os efeitos dos maus-tratos no desenvolvimento, encontraram resultados semelhantes ${ }^{9}$.

Apesar dos achados, estes autores consideram que pouco se sabe sobre o impacto da violência intrafamiliar sobre as crianças e destacam a importância da elaboração de uma teoria do desenvolvimento de crianças maltratadas capaz de guiar as intervenções, tanto clínicas, quanto sociais e políticas, além de possibilitar a verificação da eficácia dessas intervenções.

Nessa direção, cumpre ressaltar que a ajuda prestada diretamente às crianças e aos adolescentes requer, para além do conhecimento sobre as seqüelas deixadas pela violência, um aprofundamento sobre as considerações que esses jovens fazem a respeito de suas vivências, buscando por uma compreensão mais ampla de seu desenvolvimento psicossocial, no sentido de levar em conta a relação existente entre os problemas detectados e as formas de elaboração e integração psicológica dos eventos vividos. As investigações nesse campo têm privilegiado a ótica dos adultos envolvidos, sejam os pais/responsáveis ou os agentes que passam a cuidar desses jovens.

Dessa maneira, o presente estudo, tem como objetivo geral estudar o fenômeno da violência doméstica pela ótica de crianças e adolescentes vitimizados.

\section{METODOLOGIA}

Esta é uma pesquisa exploratória que busca investigar as concepções de violência pelas óticas das crianças e adolescentes vitimizados, investigando, para tanto, as concepções que têm de Família e Violência doméstica, e comparando-as com as de um grupo de jovens não-vitimizados. De modo específico, procurou-se conhecer as concepções dos dois grupos em relação aos temas em questão, para depois compará-los, procurando pelas semelhanças e diferenças entre eles.

\section{PARTICIPANTES}

Os participantes desse estudo são crianças e adolescentes com idades entre 10 e 16 anos. A escolha de abordar essa faixa etária baseia-se no fato de esse período ser o mais profícuo em relação às questões da pesquisa, visto que nessa fase o processo de desenvolvimento da identidade pessoal é bastante intenso e, em virtude de ganhos cognitivos, passa a integrar elementos da interpretação das experiências passadas, a fim de lidar melhor com o desafio das situações futuras, procedendo-se a síntese em relação à própria história de vida ${ }^{10}$.

Os sujeitos encontram-se agrupados em duas sub-amostras. O primeiro (grupo 1) foi composto por 17 crianças e adolescentes (10 do sexo masculino e 7 do feminino), com idades entre 10 e 16 anos (com idade média de aproximadamente 14 anos) que, devido a uma avaliação técnica, foram considerados em situação de vitimização e, por conseqüência, retirados da guarda de seus pais e/ou responsáveis, estando, no momento da pesquisa, sob medida de proteção, acolhidos em instituições de abrigo. Todos os integrantes deste grupo freqüentavam a escola.

Apesar da dificuldade em se obter informações claras e precisas concernindo outras variáveis, os dados coletados indicam que a forma de maus-tratos mais recorrente, em meio ao grupo, é a negligência, e o tempo médio de abrigamento transcorrido de aproximadamente 4,7 anos.

Quanto à composição da família de origem, detectou-se uma variação média de 2 a 13 pessoas, com grau de parentesco, co-habitando na mesma residência, por ocasião da vitimização, com exceção de um caso em que se afirmou não haver grau de parentesco algum entre os adultos e a própria criança investigada.

No que se refere à ocupação dos familiares (pais e/ou responsáveis), 11 participantes relataram 
que pelo menos uma pessoa da casa trabalhava fora, enquanto as outras respostas se referiram ao estudo, ao trabalho doméstico (cuidar da casa), sendo que um participante não forneceu esse dado.

O nível de escolaridade dos responsáveis está concentrado predominantemente no Ensino Fundamental, havendo apenas uma referência de Ensino Médio. Além disso, 5 entrevistados relataram que pelo menos um dos adultos responsáveis nunca estudara. Dois participantes não forneceram essa informação, alegando desconhecer a informação.

O segundo grupo (grupo 2) compreendeu 27 sujeitos (13 do sexo masculino e 14 do feminino), crianças e adolescentes com idades variando entre 10 e 15 anos (sendo a média de idade de aproximadamente 12,8 anos), que no momento da coleta residiam com suas famílias.

Esses sujeitos foram cooptados através de uma escola da Rede Pública Municipal, situada na periferia da cidade de Ribeirão Preto-SP, após autorização da Instituição e consentimento dos pais e/ou responsáveis.

Em relação às outras variáveis, pode-se dizer que o número de pessoas co-habitando na mesma residência, incluindo o próprio jovem, variava de 3 a 13 pessoas. Todos os participantes relataram ter algum grau de parentesco com as mesmas. Pelos dados fornecidos, pode-se afirmar que essas famílias, em sua maioria, têm a presença de ambos os pais (17 famílias), e algumas (3 famílias) caracterizam-se pela convivência de membros da família estendida (primos, avós, etc.). Observa-se também que 4 famílias são monoparentais (o pai é falecido ou divorciado da mãe). Por fim, têm-se as famílias reconstituídas (6), nas quais o pai ou a mãe têm novos companheiros, que convivem com o participante. Em todas as famílias, pelo menos um dos adultos possui um emprego.

O grau de escolaridade dos adultos responsáveis vai desde o nulo até os que cursaram o $3^{\circ}$ ano do Ensino Médio. A maioria teria completado o Ensino Fundamental (31 adultos), e outros foram até o Ensino Médio (8 adultos), havendo a indicação de um (1) adulto estar cursando o Ensino Superior. Em 5 casos não se obteve essa informação.

\section{QUESTÕES ÉTICAS}

Para a efetivação desse estudo, os cuidados éticos, segundo o preconizado na resolução 196/96 do Ministério da Saúde, tais como o sigilo quanto aos dados obtidos, a importância da anuência e assentimento das próprias crianças e responsáveis, do suporte a ser dado à criança, pelo pesquisador, quando necessário, assumiram grande importância.

No que tange as instituições, o procedimento consistiu no estabelecimento de um primeiro contato para a apresentação, aos responsáveis, dos objetivos da pesquisa e de uma cópia dos instrumentos que seriam empregados junto aos jovens.

No caso dos abrigos, solicitava-se aos agentes institucionais que apresentassem à pesquisadora os jovens que se enquadravam na faixa etária de 10 a 16 anos. Após a apresentação, a pesquisadora dirigiase para um local mais reservado, com cada um dos participantes para explicar o projeto de pesquisa, garantindo-Ihes o sigilo, o anonimato e a possibilidade de desistirem da participação em qualquer momento.

Quanto à coleta na Escola Pública, o procedimento foi praticamente o mesmo. À pesquisadora foi propiciado o contato com algumas classes compostas por jovens com idade variando entre 10 e 16 anos. $\mathrm{Na}$ seqüência, a pesquisadora era apresentada à classe e fazia a proposta da pesquisa, deixando com os alunos interessados um Termo de Consentimento Livre e Esclarecido, dirigido aos pais e/ou responsáveis. Apenas os alunos que trouxeram este assinado puderam participar da pesquisa, num momento subseqüente.

Tal como nas Casas Abrigos, os alunos participantes foram conduzidos individualmente a uma sala reservada para a aplicação dos instrumentos.

Por fim, procurou-se junto a agentes da instituição escolar, verificar, a partir dos nomes dos sujeitos, se em meio ao grupo havia algum com história familiar de intervenção do Conselho Tutelar, de modo a excluílos, visando controlar o fato de não vivenciarem, reconhecidamente, problemas em seus lares. Isso, contudo, não foi detectado, tendo-se guardado o número total de sujeitos investigados. 


\section{MATERIAL E ANÁLISE DE DADOS}

O material utilizado para a realização desse estudo foi composto de 3 instrumentos complementares:

a) Um roteiro para a realização de uma Entrevista Estruturada composto por itens de caracterização como idade, sexo, composição familiar, grau de escolaridade e profissão dos familiares e o grau de escolaridade do próprio participante;

b) Questionário semi-estruturado, baseado no "Jogo das Sentenças Incompletas" ${ }^{11}$, em que o entrevistador lê para o sujeito sentenças que abordam temáticas específicas, tendo-o instruído, previamente, para completá-las com a primeira frase que vier à cabeça, sem preocupações com a forma da resposta (concordância verbal ou tamanho da frase) ou com sua exatidão, na medida em que não há respostas certas ou erradas.

No caso desse estudo, um "Jogo de Sentenças" foi especialmente preparado: 1) Família é...; 2) Uma família feliz é aquela que...; 3) Uma família infeliz é aquela que...; 4) Eu queria que minha família...; 5) Eu acho que quem cuida de criança ou de adolescente deveria...; 6) Uma criança/adolescente para ser bem educado precisa...

c) Um roteiro com duas questões abertas baseado em procedimentos propostos por Sanches ${ }^{12}$, visando uma investigação direta das vivências do participante em relação a sua família. As questões empregadas foram: 1) Você se lembra de alguma coisa legal que aconteceu com você e sua família? Conte como foi...; 2) Você se lembra de alguma coisa ruim que aconteceu com você e sua família? Conte como foi...

As informações obtidas com a aplicação desses instrumentos foram tratadas através do método quantitativo-interpretativo que consta de dois momentos: a) A investigação das respostas obtidas de forma a agrupá-las de acordo com a proximidade de sentido e b) A categorização dessas a partir de uma análise minuciosa de cada resposta, de forma a promover condições para um agrupamento válido dos dados ${ }^{13}$.

Essa análise que, a princípio é qualitativa, justifica-se pelo fato de os dados serem predominantemente descritivos ${ }^{14}$. Assim, as respostas dadas às "Sentenças Incompletas" e às "Questões Abertas" são agrupadas e categorizadas de acordo com o tema e com o conteúdo, de modo a delinear as concepções/opiniões dos sujeitos ${ }^{15}$.

Na seqüência, verifica-se a freqüência com que as respostas iguais ou semelhantes foram dadas, visando ponderar a prevalência das categorias para cada grupo em particular e, depois, em relação ao outro.

Os dados coletados a partir de cada um dos instrumentos foram analisados separadamente, para em seguida buscar-se o estabelecimento de possíveis relações entre os diferentes resultados.

Visando validar o procedimento de análise, categorizações foram realizadas por dois juízes em separado, para, em seguida, serem confrontadas e reformuladas, com base em um consenso.

\section{RESULTADOS E DISCUSSÃO}

Os jovens, de modo geral, definem a família como algo preponderantemente positivo, seja em atributos e/ou características que satisfazem as necessidades do jovem. Nesse sentido ela é também preponderantemente concebida da forma "estática". Somente em alguns casos, para ambos os grupos, o aspecto positivo é atribuído a uma dinâmica, em que se concebe um intercâmbio maior entre os membros.

Em contraposição a essa tendência majoritária de caracterizar positivamente o conceito de família, há um sub-grupo, tanto de vitimizados como de não vitimizados, que tende a uma descrição assentada em aspectos concretos, desprovidos de valoração, seja ela positiva ou negativa. Se no primeiro caso 
pode-se aventar uma espécie de idealização (possivelmente, apoiada em idéias convencionais a respeito de família), no segundo pode-se cogitar uma certa dificuldade em relacionar família a sentimentos, pelo menos para reproduzir o ideário convencional.

Há ainda que se atentar que a única diferença constatável, passível de efetivamente ser considerada entre os dois grupos, diz respeito à presença de dois tipos de respostas que os vitimizados dão e os outros não: a família associada a bens materiais e a presença de respostas evasivas.

O tema de bens materiais relacionados ao próprio conceito de família, talvez, faça sentido num contexto de institucionalização na medida em que muitos dos casos de abrigamento têm como pano de fundo dificuldades financeiras, que findam por determinar a própria dissolução da unidade familiar.

Em relação às respostas evasivas, pode-se cogitar uma dificuldade maior para alguns abrigados em definir família, na medida em que a institucionalização concorre para um enfraquecimento desse referencial de origem para a criança.

Referindo-se ainda ao tema família, quando indagados a respeito da concepção de família feliz, notou-se uma clara tendência, em ambos os grupos, em relacionarem-na com aspectos positivos de convívio, dando certo destaque à dimensão dinâmica do funcionamento familiar, sobretudo no caso dos abrigados que, em contraposição ao outro grupo, parece não descartar a possibilidade de haver conflitos ou, mais exatamente, não atrela felicidade familiar à ausência desses, mas sim à união e ao bom entendimento entre os membros.

Contudo, vale a ressalva referente ao fato de os resultados obtidos na sentença seguinte, sobre a concepção de família infeliz, permitir uma associação entre infelicidade e ruptura familiar (à falta de convivência), que aparece no grupo de jovens vitimizados e não no outro grupo.

Também chama a atenção o fato de a categoria de respostas evasivas concentrarem um número razoavelmente maior no caso dos jovens institucionalizados, em comparação aos não, tanto em relação à concepção de família feliz (vitimizados = $23,5 \%$ e não vitimizados $=0 \%$ ) quanto infeliz (vitimizados $=23,5 \%$ e não vitimizados $=3,7 \%$ ).

Vale atentar ainda para a presença de respostas que destacam os bens de consumo como condição para a existência de felicidade familiar no caso das crianças que moram com suas famílias, refletindo possivelmente aspectos do ideário do atual contexto sócio-cultural.

Em contrapartida a questão material e, na mesma linha, a necessidade de trabalhar, só aparece para os abrigados quando correlacionada à concepção de família e família infeliz, de maneira que se pode cogitar a associação feita entre essa dimensão e os problemas na base do abrigamento do jovem.

Quanto aos desejos e/ou expectativas em relação à família de origem, pode-se dizer que, de modo geral, grande parte dos sujeitos dos dois grupos indica um desejo de maior convivência ou proximidade física com os familiares e de obtenção de uma dinâmica familiar mais positiva, permeada por mais sentimentos positivos, que garanta a felicidade ou, pelo menos evite a infelicidade. De forma isolada, alguns desejam alterações de aspectos concretos da configuração familiar.

De modo à parte, há um conjunto de respostas obtidas somente junto aos sujeitos que vivem em suas famílias, indicando diferentes desejos em relação à família, desde a ascensão social até o de que permaneça do modo que está.

Quanto aos institucionalizados, a diferença reside no aparecimento exclusivo da categoria de não respostas (não sabe $=11,8 \%$ ), que pode apontar para uma possível dificuldade desses, no momento em que se encontram, para identificarem com clareza suas expectativas em relação à família de origem.

Tratando-se especificamente das questões abertas, os resultados obtidos permitem alguns destaques. Em relação aos eventos positivos, chama a atenção o fato de o grupo de jovens abrigados apresentar uma grande concentração de respostas evasivas (33,3\%). Na mesma linha, eles também dão 
um número relevante de respostas em que o evento positivo exclui a presença de familiares, havendo inclusive quem, de modo direto, associe o evento positivo ao afastamento da família. Nesse sentido, pode-se dizer que para mais da metade do grupo $(66,5 \%)$ a tarefa de lembrar eventos positivos envolvendo a família é bastante difícil, ao passo que essa mesma característica, para o grupo de crianças que vivem com suas família é menos intensa (girando em torno de 20\%). Este, destaca-se mais pela sua capacidade de lembrar eventos positivos envolvendo a família, sejam eles eventos de lazer específicos, como festas, passeios, etc., e também por se referirem a aspectos da rotina familiar como sendo prazerosos, bem como à própria relação, dimensões inexistentes nos abrigados.

É preciso cogitar que essa diferença entre os grupos pode ter um significado psicológico profundo, mas pode também ser atribuível ao processo de institucionalização e/ou ao tempo de afastamento da família, pela interferência que este pode ter na memória dos jovens (que para alguns é de anos).

Quanto aos eventos negativos, houve um paralelo entre os dois grupos. Contudo, os jovens abrigados se destacam no sentido de darem um número maior de respostas que findam por evitar a associação evento negativo e família, ou seja, a maior concentração de respostas se refere a situações em que o sujeito está sozinho ou emite respostas evasivas de difícil categorização (47,3\%).

Embora o grupo 2 também apresente respostas desse tipo, o número é menor (16\%), sendo que a concentração maior para esse grupo refere-se a perdas (morte de parentes - 42\%).

Vale novamente a ressalva quanto ao fator institucionalização para explicar tais diferenças.

Por fim, é preciso apontar um tipo de resposta que aparece somente nos abrigados, e que embora pouco representativa do ponto de vista numérico (5,2\%), tem uma relevância qualitativa: as perdas materiais da família. No contexto brasileiro esse tipo de evento pode ser decisivo para a manutenção da família e, ainda, estar na base de parte dos abrigamentos realizados, sobretudo, em casos de negligência, face aos quais uma distinção acurada entre dificuldades econômicas para cuidar adequadamente dos filhos e uma desresponsabilização é difícil.

\section{CONSIDERAÇÕES FINAIS}

A partir dos resultados apresentados e discutidos neste trabalho, faz-se algumas considerações, a título de conclusão.

Primeiramente, é preciso dizer que grosso modo não foram detectadas grandes diferenças entre os dois grupos estudados quanto às idéias/concepções a respeito dos temas família e violência. De modo geral, parece haver uma tendência a respostas de caráter convencional.

Contudo, na contramão disso, chama a atenção o fato de haver um grande número de respostas evasivas que, embora aparecendo em ambos os grupos, é mais freqüente no grupo dos jovens abrigados, o quê faz pensar nas dificuldades generalizadas desses jovens expressarem-se verbalmente, emitindo suas opiniões/reflexões sobre temas experienciados. De modo mais particular, podese também cogitar o fato de os temas abordados mobilizarem emocionalmente determinados sujeitos, a tal ponto que a expressão torna-se mais difícil, sem, obviamente, esquecer da situação artificial criada pela pesquisa em si.

Uma outra consideração importante relacionase à detecção de respostas, no grupo de jovens abrigados, que refletem o desejo intenso de estarem com suas famílias. Esse dado suscita algumas questões no sentido de refletir sobre as razões subjacentes ao abrigamento ou, pelo menos, sobre as percepções que os jovens têm dessas razões. No caso de as vitimizações serem inegáveis, estarse-ia diante de jovens que podem se colocar em situação de risco pela própria incapacidade de fazer a crítica necessária à qualidade das práticas de cuidado/educação a que são submetidos.

Levando em conta a complexidade do tema e a necessidade de maior aprofundamento das questões, pode-se dizer que o presente estudo, dado 
seu caráter exploratório, tem o mérito de lançar muitas indagações para novas pesquisas.

Dentro disso, vale também alguns comentários sobre a metodologia empregada. Apesar de concorrer para a produção de certas respostas estereotipadas, o instrumento "Jogo das Sentenças Incompletas" mostrou-se muito útil no sentido de estabelecer um clima propício à coleta de dados ao proporcionar uma interação de caráter lúdico com os sujeitos, tendo em vista sua idade e os temas abordados.

As questões abertas baseadas em eventos específicos, por sua vez, também se mostraram muito interessantes e eficientes, sobretudo num estudo que busca elucidar questões relacionadas a risco psicossocial e desenvolvimento humano. Deve-se atentar para o fato de terem sido empregadas no fechamento da coleta, o que provavelmente proporcionou o aumento de sua validade.

De maneira geral, a melhor característica dos instrumentos empregados está na praticidade, rapidez e facilidade de aplicação, além propiciarem uma escuta diferenciada dos jovens, apoiada no valor concedido às suas opiniões/concepções, freqüentemente desprezadas nas investigações científicas. Faz-se importante reafirmar que há uma necessidade de serem realizadas mais pesquisas que se preocupem com a ótica das vítimas da violência, sobretudo as crianças e adolescentes, uma vez que se quer considerá-los como sujeitos de seu próprio processo de desenvolvimento.

\section{REFERÊNCIAS}

1 Saffioti HIB. A síndrome do pequeno poder. In: Azevedo MA, Guerra VNA, organizadores. Crianças vitimizadas: a Síndrome do Pequeno Poder. São Paulo: Iglu; 1989. p.13-21.

2 Oliveira AB. Saúde e vitimização. In: Azevedo MA, Guerra VNA, organizadores. Crianças vitimizadas: a Síndrome do Pequeno Poder. São Paulo: Iglu; 1989. p. 99-103.

3 Guerra VNA, Santoro Júnior M, Azevedo MA. Violência doméstica contra Crianças e Adolescentes e Políticas de Atendimento: Do silêncio ao compromisso. Rev Bras Cresc Desenv Hum 1992; 2 (1): 71-96.

4 Fuster EG, Ochoa GM. El maltrato infantil: un análises ecológico de los factores de riesgo. Madrid: Ministerio de Asuntos Sociales. Dirección de Protección del Menor;
1995. El impacto de los malos tratos en el desarollo psicossocial del niño. p.49-63.

5 Cerezo MA. El impacto psicológico del maltrato: Primera infancia y edad escolar. Rev Infancia Aprend 1995; 71:135-57.

6 Azevedo MA, Guerra VNA, organizadores. Crianças vitimizadas: a Síndrome do Pequeno Poder. São Paulo: Iglu; 1989. Conseqüências psicológicas da vitimização de crianças e adolescentes. p.143-63.

7 Bringiotti MI. Maltrato infantil - factores de riesgo para el maltrato físico en la problación infantil que concurre a las escuelas dependientes del Gobierno de la Ciudad de Buenos Aires. Madrid (España) - Buenos Aires (Argentina): Niño y Dávila; 1999b. El impacto de los malos tratos en el desarrollo psicosocial. p.67-70.

8 Bringiotti MI. Maltrato infantil - factores de riesgo para el maltrato físico en la problación infantil que concurre a las escuelas dependientes del Gobierno de la Ciudad de Buenos Aires. Madrid (España) - Buenos Aires (Argentina): Niño y Dávila; 1999a. Criterios para establecer la definición y las tipologías del maltrato infantil. p.37-48.

9 Aber JL, Allen JP, Carlson V. The effects of maltreatment on development during early childhood: recent studies and their theoretical, clinical, and policy implications. In: Cicchetti D, Carlson V, organizadores. Child maltreatment: theory and research on the causes and consequences of child abuse and neglect. Cambridge (USA): Cambridge University Press; 1989. p.579-619.

10 Fierro A. Desenvolvimento da personalidade na adolescência. In: Coll C, Palacios J, Marchesi A, organizadores. Desenvolvimento psicológico e educação: psicologia evolutiva. Porto Alegre: Artes Médicas; 1995. v. 1. p.288-98.

11 Raffaelli M, Koller SH, Bandeira DR, Reppold C, Kuschick $M$, Dani D. Exploring the lives of brazilian street youth using a sentence completion task and a structured interview. In: 1st Urban Childhood; 1997; Noruega: Child Hope 1997; 1: 142.

12 Sanches CS. Crianças e adolescentes em situação de rua: estudo qualitativo realizado na cidade de Marília SP. [tese]. Marília: Faculdade de Filosofia e Ciências, Universidade Estadual Paulista; 2001.

13 Biasoli-Alves ZMM. Intersecções das abordagens qualitativas e quantitativas. In: Souza DG, Otero VR, Biasoli-Alves ZMM, organizadores. Anais da $18^{a}$ Reunião Anual de Psicologia da Sociedade de Psicologia de Ribeirão Preto; 1998. Ribeirão Preto, 1988, p.487-89.

14 Lüdke M, André MEDA. Pesquisa em Educação: abordagens qualitativas. São Paulo: EPU; 1986. Abordagens qualitativas de pesquisa: a pesquisa etnográfica e o estudo de caso. p. 11-44.

15 Biasoli-Alves ZMM, Dias da Silva MHGF. Análise qualitativa de dados de entrevista: uma proposta. Paidéia: Cad Psicol Educ 1992; 2: 61-9. 